\title{
The Occupational Symptoms in Bus Driver in Brazil and \\ Psychoanalytic Contribution: A Descriptive Research
}

\author{
Alcantara Vanessa Carine Gil, Andrade Silva Rose Mary Rosa Costa, Ramos Eliane Pereira \\ Federal Fluminense University, Rio de Janeiro, Brazil
}

\begin{abstract}
Since ancient times, the physiological processes of the human body have been studied in a constant search for understanding always seeking the treatment of possible malfunctions. For Freud, the disease took a different meaning since language is the bridge between the unconscious and the symptom. The bus drivers job requires a balance between the body and the psyche. Interventions are needed to ensure the care of them. The role of psychology to meet the bus driver goes beyond the technical processes. Listening is a way of signifying the condition suffered by the subject as the psychologist is convened to hear beyond recruitment and selection, and a translator of the unconscious or the symptom means. The consideration of Freudian psycho analysis says about the guy who is immersed in the process of speech, his/her body also has its own language. And from this premise, this paper aims to analyze the current condition of the road professional regarding the symptoms and psychological state, relate to contemporary reality considering documentary analysis of the organization and the methodology used is descriptive research.
\end{abstract}

Keywords: body, bus driver, psychoanalysis, work

\begin{abstract}
About the Garage and the Function of the Work
The tone is not poetic or methodical or melancholy, is a metaphor that explains as compared with the human body, being a board awareness that serves to transcend what is only sensitive to the eyes, the management is the brain capable of coordinate all the complex workings of the other parties, planning corresponds to the inner ear. It is responsible for the direction. The traffic is the feet leading the direction given by planning, since the administration is the lungs able to maintain brain function and heart. Coordinators lines can be compared to the eyes, which alert and vigilant by good operational performance. And dispatchers are like the veins directly connected to the heart and help in maintaining the vitality of heart. The instructor can be likened to the hands that perform a function the law can be compared to the immune system of the body responsible for the defense of all parties. The personnel department can be considered as the nose that is directly connected to the administration, the image editing in autobus Fagundes has memory function, as in the human body, where they are recorded facts. The scale equates to the muscles of the body, which gives

\footnotetext{
Alcantara Vanessa Carine Gil, master, Post Graduated in the Psychosomatic Transdisciplinary Care and Body, Department of Human and Organizational, Federal Fluminense University.

Andrade Silva Rose Mary Rosa Costa, Ph.D. philosopher, Ph.D. in Nursing, Coordinator of the Specialization Course in Psychosomatic Transdisciplinary Care and Body, Teaching of Federal Fluminense University, Federal Fluminense University.

Ramos Eliane Pereira, Ph.D. in Nursing, professor of the Specialization Course in Psychosomatic and Transdisciplinary Care and Body, Teaching of Federal Fluminense University.
} 
movement to the body autobus Fagundes. And tourism is the stomach-a source of energy and absorption to body maintenance. Clients are the pillar that sustains the whole body autobus Fagundes. Finally, the function of psychology within the company is similar to endorphins in the human body —an analgesic can soothe the excesses and facilitate the well-being of the whole.

The bus drivers perform an indispensable service, their job is to lead and bring people to their jobs, school, hospital, mall, airport, college, church, walking, every day thousands of people depend on the bus to move from one place to the other. And on the bus, people know, talk, sleep, eat, read, write, finally, live, the work environment of the driver's lane and the bus. The goal of drivers is to carry safely those who depend on their ability of driving, therefore, this profession is essential for life after contemporary, in which thousands of people depend on the bus to move around.

The works occupies a place of great importance in the process of human living, being relevant result in the expression of subjectivity of workers and allowing their participation in planning and organizing work. This participation can bring knowledge workers overall work process, avoiding the alienation and suffering and promoting the enjoyment and well-being in labor activity. The work includes the subjectivity of each subject and can be a source of pain and fatigue for some and pleasure for others (Silva et al., 2008, p. 5). The work is part of man's life; it enables us to have resources for us to pay our bills, and also improves our quality of life. To what extent? This is an issue, as the role is being a symptom, the possibilities of motivation and good will yield fading.

The psychodynamics of work is stressful and this factor does not change because the work demands responsibility, pressure. Every activity requires an investment psychic by the worker and the activity becomes heavier and source of dissatisfaction.

Dejours (1996) considered the significance and outcome of suffering as an essential dimension in understanding the relationship between health and work, which reveals the importance of listening to workers, better understanding and providing visibility, and making sense of what happens in labor relations (Milani, 2007, p. 3) ${ }^{1}$. Thus, the proposed development of this work takes into account the proposal transdisciplinary important for contemporary thought and contributes to the renewal of academic thinking about the work itself. The disciplinary research with respect to a maximum one and the same level of reality, indeed in most cases it only a concern fragments of one and the same level of reality.

When the work is a place of satisfaction and appreciation of the professional environment, the likelihood of this is great ill since suffering for the individual can be considered as an escape. Depending on the climate in the environment, psychic charge accumulated must be discharged in order to balance and decrease the voltage. If the voltage excessive psychological burden the possibility that the body reflects disequilibrium, the work that the subject does not offer the freedom necessary for them to use their skills in the exercise of their activity results in suffering. Interpersonal conflicts are one of the consequences of psychological distress, and the defense in front of teammates is reinforced by fear of being harmed, yet this fear is unconscious. Work as a place of meaning construction should lead the subject to realization and liberation of man. After our professional choices have to do with our inclinations to psychic satisfaction, desire is a mediator between our ability and actually be.

\footnotetext{
${ }^{1}$ This article approach what we see in the garage the workers sometimes don't talk about their suffering cause they have fear of lose their job.
} 


\section{Language Blind Deaf and Dumb}

I shut up. Everyone agrees that frustrate the speaker, it all before, and I also. Why? If the frustrating, is that I asked for something. (Nasio, 2010, p. 242)

Garcia-Roza ${ }^{2}$, in his book: Introduction to Freudian Meta Psychology Lectures on Language in Freud considered that the territory of language defines a place that is conceived by Freud as a whole, as something that cannot be divided or fragmented into "centers", but as something unitary, indivisible, and only in relation to something of this kind can employ the term appliance (p. 37).

Freud began to think about the effects of this language in the subject, but its influence is not isolated, and it will constitute from learning and also made from another machine language. At birth, the subject does not have the apparatus ready language. Building such a process is time-consuming, but it promotes knowledge about the world and connection with others. Garcia-Roza (2008) said that the device language in Freud later be renamed as the psychic apparatus, "This learning Freud describes in terms of stages of neurological training of the language, and the starting point of his analysis is the representation—word” (p. 40).

In reading Freud, Garcia-Roza (2008) stated that the word psychology is an element baseline language function and representatives: acoustic image, visual image, the motor image of language, and writing.

If the portable language constituted this necessary relationship with another machine language representation, if every-word has a different extent depending on the other device to which it is intended, then the machine language is a construction implying a perpetual reconstruction. (Garcia-Roza, 2008, p. 44)

The passage of the machine language for the psychic apparatus can only be considered a change in nomenclature as the device language was capable of meaning and also produce effects in the subject. Garcia-Roza (2008) showed the device language designed with the realm of the unconscious (p. 65).

The truth is that the machine language produced by Freud overflowed the strict limits of a machine language and was established as the first Freudian model of the psychic apparatus. (Garcia-Roza, 2008). The text of Freud "About Aphasia" presents concepts that will later be pillars for psychoanalytic theory and that will make a difference in the clinic, such as repression, misdeed, condensation, and displacement. And this work shows us that Freud refused to work with neurology since its formation was first and instrumentalized for their productions on the human psychic constitution.

The ability of patients to talk about their needs and about their everyday ailments allows an update in people's conscious thoughts, and the articulation of the unconscious takes place there every moment. There is no way to fight only the interpretation and an appropriate environment for the unconscious appearance opens avenues for analytic success cases and ultimately remission of symptoms that torments.

Speech is more than expressed a set of articulated sounds and letters, it is present even when the subject is unable to speak. Speech inserts the subject culture, and enables social development. As shown in the film The Enigma of Kaspar Hauser, if the guy does not live in society and is embedded in a culture, he does not develop the simplest skills, such as walking, eating, as well as family, and/or caregiver is a mirror for the subject, and society is too. The language is not born with the subject, it itself has instruments that may arrest it, but it is structured from the stimulation of the other. In introducing the world of meanings, the language enables our communication more effective speech. And it is through the linguistic process and their meanings that men,

\footnotetext{
${ }^{2}$ Luiz Alfredo Garcia-Roza (born 1936 in Rio de Janeiro) is a retired Brazilian professor and current novelist. As an academic he wrote philosophy and psychology textbooks. Wikipedia, Brazil.
} 
according to Lacan, enter the discourse of the big other.

Human language is a compromise between self and other. What between the subject who speaks and the listener is a screen, a protection, a kind of wall that rises even when there is silence. Between two human beings is always the wall of language (Long, 2006, p. 7).

But in psychoanalysis, the value of language is not directly connected only to the sense of speech. Freudian theory goes further and teaches the language errors demonstrating wealth of meanings. Materials repressed in favor of unconscious pleasure are filled with anguished calls of the subject. Forgetfulness, jokes, and deception, serve psychoanalytic interpretation with a plate detailed to be unveiled. For Freud, those are phenomena that have meaning and intent. Though seemingly unintentional, that has valid reasons which can be discovered in analytical research (Long, 2006, p. 25).

Lacan conceives that language goes through the relation of the thing and the signifier and the psychic apparatus works as stated earlier, to give meaning that those who have no sense. When trauma undergoes a symbolic way, it tends to dissolve. The repetition is heavily thereof.

For psychoanalysis, the unconscious subject is an effect of the signifier, is subject to significant chain together with its unconscious tools. In other words, the subject of psychoanalysis is a significant effect (an effect of language): It is under significant and goes to the big other - the unconscious (Long, 2006, p. 48).

We can say that the search for absolute satisfaction of the human being is a movement, not life. The driving is insatiable in the complaint, for example, that hysteria is joy, and there is no object that satisfies the driving, so the desire is maintained by dissatisfaction. In hysterical obsession, there is a huge effort for the satisfaction of the big other, or in any way cover the fault. It does not complain of the big other and shows no lack of it. Just enjoy it while enjoying the big other denies hysterical.

The focus of transportation companies is the product that they sell: traveling, but without people, that service does not hold up. After all, the buses are not automatic. Let us remember that the Industrial Revolution brought technological advances, growth for the countries, but also in the opposite, various pathologies appeared. Illnesses were linked to reflections of accidents, toxic substances, and even more subjectively psychic. When the working condition overflowed the psyche, then the symptom arises, "A period of expansion of the Taylor-Ford model that exposes the body as the point of impact of exploration" that is left to suffering and is subject to contemporary psychiatrist Dejours (1996). Such suffering is a way of defense, building it means resorting health and distorting the perception of work, they are psychic tools that are established to try to cope with the unbearable effects that the work will cause, lack of working often makes the psychic sense poor. Faced with so many boundaries of contemporary society and suffering at work, the rescue worker not only motivating him/her as making himself/herself able to fully perform your work is essential. This research is relevant regarding the collective care organization, and it is hoped that this research will effectively practice this proposed work in organizations of this size in the metropolitan region of Rio de Janeiro. According Bertan (2009, p. 18), anxiety disorders are among the most common psychiatric disorders frequent in the general population, in the same way as anxiety symptoms. The stress is both a modifier of conduct, and we can considered stress one rate of wear and tear of the body. Dejours (1998, p. 27) stated that the first victim of the system is not the psychic apparatus, but the body is docile and disciplined.

Considering the man is a bio-psycho-social-spiritual study about their lifestyle, psychosocial factors which are undergoing and responding make it necessary for an understanding of how this professional macro reacts to impossibilities. As the psychodynamics of work is stressful, and this factor does not change because the job 
responsibilities, demand, and pressure. Every activity requires an investment by the worker's mental activity to become heavier and source of dissatisfaction. Dejours (1996) considered the significance and outcome of suffering as an essential dimension in understanding the relationship between health and work, which reveals the importance of listening to workers, better understanding and providing visibility, and making sense of what happens in labor relations (Milani, 2013, p. 3). Again we see that stress is a reaction to dissatisfaction, which is chemical reaction that interferes, and is inscribed in the psyche of the subject and an effective way cathartic that shows up when the driver can verbalize this high price he/she paid daily.

\section{The House of Life: The Human Body in Performance and Limitations}

"My body is a garden, my desire their gardener", this phrase belongs to William Shakespeare. We could continue it by stating that insects are the symptoms. In a garden what arises can be more beautiful, after all, it has a privileged location. In front, the first place goes to enter the house. A beautiful garden has a beautiful grass. Trimmed trees are full of fruit. Assorted flowers give it a unique touch. There are those who like to have benches in the garden, and some like to adorn it with porcelain items, and some forbid anyone to step on the grass, putting all garden demands with the care of a gardener. After all, he/she is responsible for the maintenance of the same, insects, plus the phrase are considered symptoms of the garden. After all, the same that brings damage to the garden also promotes renewal. So is the human body ${ }^{3}$, endowed with life, should be adorned, fed, preserved, carefully listened to, understood, loved. Among these cases, the body is invaded by symptoms as well as the garden is invaded by insects. It is not known where they came from or where it will go. The unknown afflicted damage often cannot be avoided, as treatment begins only after the physical manifestation. The body hitherto manifested little clues and signs of what he/she was going through, just like the garden demonstrating the care and oversight of the gardener. In psychoanalysis, approaching Shakespeare, that will be uttered by the desire, that in psychoanalytic theory, it is a realization unconscious, so the garden (the body) is governed by this desire. If there is no maintenance on the psychic body suffers, the body care is essential to decrease the voracity of the unconscious. We know that not always physical care is sufficient for the unconscious, which needs constantly make a claim in order to be interpreted. And the conscious is defense against insect called symptom which is established to affirm fake omnipotence gardener. Every care is insufficient because sometimes the own garden produces a flashy for insect established, if the function failed gardener, and insects infest the garden. There is the need of the function gardening expert, the analyst in psychoanalysis has this function: mean inputting symptom and enabling the body to respond to the attack of symptoms creatively, remission of insects depend on the possibility of the garden without them. Because in some cases, the insects bring life; and without them, the garden will succumb.

The body is the house of life, where it manifests itself in the same way as death. The body is much more than that intervention space for medicine and pills immediacy. It houses our joys and sorrows, and speaks for us before the same language. The body is a complex set of signifiers, and the insight changes according to the discourse of science which aims to study it, and explain it. The body for the coroner is source of evidence to know what caused the loss of life, for a sanitarian, body disease agent is so influenced by the care hygienist thought in the 20th century. The body is a source of pleasure and painful manifestations, home to all of us, a

\footnotetext{
3 The subject is more than himself/herself, is the sum of all its limits and possibilities, in encountering the speech loaded with symbolism and unconscious meanings taken by a body language symptom can observe the movement of the psyche to be interpreted.
} 
victim of his/her own productions, and source of social control and individual prison. The body is a source of communication through the perspective of language dream or symptom, but the challenge of health care pierces the need of fordiagnosis and treatment, transcends the function of healing, and health care leads us to something deeper: the drive of life.

For classical philosophy was the perishable body, where evil abode, the body was the prison in return for immortality belonged to the soul, for it was perfect.

The view of Greek society was admiring the body, since the gods, which were always shapely and athletic as civilization Greeks have introduced sports to the qualities of the body were highlighted. And fascination with physical strength was valued even in wars. In the Middle Ages, dark thoughts and submission to the authority of the clergy, a spot of body was sinful guilty, since the desires from him/her were considered sinful and unclean. The body was repressed, voiceless, reason for removal divine. From modern philosophy in Descartes, there was a split between mind and body, called dualistic conception, both were considered distinct. While the mind was free, the body was passive. These view further thoughts produced in a problem precisely because of this division, with the body part of the subject which is also constituted of mind, thought, and emotion. If it were divided, it would not be possible to treat symptoms, for example, as psychosomatic hysteria, and psoriasis, with the arrival of Renaissance thought, the body was made aware. At last consequences, capitalism took the body to work; disciplinary power explored the productive power of the body. Consumer object to the object consumed the concern of the new economic order established in the Industrial Revolution era with production capacity for increasing development of the capitalist market.

In the 20th and 21st centuries, the body was exposed to the super models. The media and communication vehicles produced bodies are not real, which are fanciful models of health, and are ideal for consumerism, and thus, consumed the body to lose itself. Even the capital dehumanizes the body, the production standards of perfection, rampant consumerism serves as the driving force for the establishment of the need to comply with the requirements nailed by capitalism.

The main consequence of this situation is that the bodies have been submitted, and psychiatric is increased helplessness. There has never been in the history of mankind having freedom of choice, be it religious, political, or sexual, is ideological. The man has never been arrested in his/her choices, given the diversity becomes the default option, and the subject suffers in his/her helplessness. What explains this feeling?

This is condition of helplessness? Human beings are born helpless, and this condition is universal—no baby survives after a few hours without care, and such care is essential to the life of the little being as food, maintenance of proper body temperature. In adolescence, helplessness is maximized, as the subject loses its references heroic father is no longer the omnipotent being, and the candor of childhood is transformed into an existential angst, hormones, sleeping, and ideas boiling.

It is possible that some individuals still feel helpless in the face of the clamor of sex. But this is the exception and not the rule. The rule is acceptance of sexual impulses, whatever as legitimate desires to which we assign, to fulfill ourselves as modern, released and satisfied sensual and sentimental subjects (Costa, 1999, p. 2).

Thus the helplessness of not being what it was and not knowing who leads the teen to seek their tribes, their language, their peers, and what they like, a way to minimize the anguish of loss or change of identity. Wanting to say agony or helplessness, it should be noted that these terms, which should restrict is a psychic space located beyond the anguish (Andre, 2001, p. 2). 
Helplessness in adulthood is not all bad, because from it, the subject moves in search of answers, gets out of the parked position, and releases the buffer miss. In Freud, helplessness is caused by sexual issues. Early child is barred from knowing his/her gender, and handle it by dogmas, on the subject of castration, of his/her death comes into contact with the real, feeling helpless. Saying that, "I" is not master of his/her home, because he/she was besieged by the tenant, sex is an anachronism. Owners and renters' sexual presently live in beautiful harmony prescribed by the media narcissistic society of consumption (Costa, 2000, p. 2).

Helplessness is potentiated by excessive consumerism offers at external facilities to satisfy a pseudo- to have what you cannot. As a result of this, it appeals capitalist who makes the subject-debt market mentally on their expectations and desires. The fact that the frustration caused by this lack is not fulfilled leads the subject to another stage of helplessness: the symptom.

According to what discussed above, the beginning of this conclusion states that the proposed hypothesis for this work as the symptom language has been confirmed. We consider that besides the medical conception of what the illness, the symptom in psychoanalysis we looking for human suffering is explained by the communicative structure of the symptom, in order to signal that it does not mean that in the psyche, language function is to drain that overflowed from the unconscious to the body and the symptom is indicative traversed by the need to make heard.

We know that the symptom on the body without physiological background is unconsciously trying to cope with the conflicting issues of the subject, and to seek explanations for their suffering. In the analysis, it is the meaning covered by repression before that worked tirelessly because the symptom is unknown, and not considering reductionist claiming that the etiology of nervous affections, and of psychosomatic symptoms are trademarks unconscious repressed often having accelerator as childhood trauma and sexuality too. In the Lacanian conception, symptom is originated and fruit of suppléance of the Name of the Father, having a significant role to parental responsibility for generating a symptom in the subject.

The body feels and learns discipline oneself, if condition expresses the emotional conflicts of mind, embodied in cellular tissues, and reflected in the quality of muscle tone, facial expressions, breathing rate, posture, tone of voice, etc.. Therefore, our body is shaped according to the experiences, especially those occurring in early childhood, when we find ways to defend ourselves still precarious. These events often leave deep scars and irreversible (Volpi, 2005, p. 2).

\section{Conclusions: A New Way Far Away From Symptom}

The subject's body becomes an uncomfortable matter for the house of life, symptom then leaves the place of weight and is now considered as response in decipherable through analytical work. We have seen that the words have a force incalculable and that when the subject does not express its discontent, feelings, energy contained gains via the body.

Occurs Fernandes said that today the presence of the body in psychoanalysis goes beyond somatic complaint, i.e., the body is also present in the negative. Thus, the body that is the subject of psychoanalysis beyond the somatic and is a functioning whole consistent with the history of the subject.

The body for psychoanalysis is not a primary experience for the subject. It only has access to the body through a series of actions that are performed by the symbolic. Psychoanalysis makes a transition from the logic of anatomy to the logic of representation. The body of psychoanalysis is then traversed by a body language. In terms, Lacanian language is crucial in discerning and body constitution. The symbolic body makes the real 
body incorporated (Neto, 2008, p. 5).

One should also note that at the time that Lacan proposes language as "subtle body", it introduces the disjunction between subject and body. Indeed, the definition of the subject implies significant chain of the unconscious but not the body. And it is a structural need to move to a conjunction between the signifier and jouissance that Lacan takes to introduce the concept of being speaker who then appoints the joy of the body (Izicovich, 2009, p. 1).

We should not forget the bridge proposed in this work between Cross-Disciplinarily and Psychoanalysis as a professional position committed to human, notwithstanding the coolness of meaning and commitment to be the model tries to inculcate scientific attitude as treatment.

The specialized science does not explain life. This only makes sense, when it contextualized through all the accumulated knowledge, recognizing the right of every human being, whatever its truth, religion, gender, culture, and race to exist and inhabit this planet, living and contributing, respecting and being respected for individual and group differences.

It can be concluded that where there is no room for the subject, appears the symptom taking voice, word, or beyond, the meaning of the word that frees the bus driver of the symptom since introducing another dimension: the speech and signification of the senses, senses those that often gets lost by a disrespectful word of a customer, that is lost due to the possibility of overtime. Open space for listening, means the symbolic and symptom that gives way to a new path, the change in thinking, the creative begins to appear and in the case of the bus driver is not setup to repeat the path that went wrong.

\section{References}

Andre, J. (2001). Between distress and helplessness. Agora (Rio J.), 4(2), 95-109.

Bertan. F. C. (2009). Quality of life, anxiety, depression and sexual satisfaction of adults with cancer. Retrieved from http://biblioteca.asav.org.br/vinculos/tede/FernandaBertonPsicologia.pdf

Costa. J. F. (2000). The psycho analytic myth of helplessness. Now Magazine, 3(1), 25-47.

Dejours, C. (1996). A new vision of human suffering in organizations (pp. 149-174). In J. Chanlat (Ed.), The individual organization. São Paulo: Ed Atlas.

Faiman, C. J. S. (2012). Occupational health. São Paulo: Psychoanalytic Clinic.

Garcia-Roza, L. A. (2008). Introduction to metapsychology Freudian about aphasia project 1895 (Vol. 1). Brazil: Jorge Zahar.

Izicovich, L. (n. d.). The body symptom. Retrieved from http://www.champlacanien.net/public/docu/4/rdv2010pre1.pdf

Lazzarini, E. R. \& Viana, T. C. (n.d.). The psychoanalytic concept of the body or that body is psycho analysis? Retrieved from http://www.fundamentalpsychopathology.org/8_cong.../TR_439.pdf

Long. L. (2006). Language and psychoanalysis. Brazil: Jorge Zahar.

Milani, H. F. B. (2013). Looking for a job in the suffering. Retrieved May 2, 2013, from http://www.saudeetrabalho.com.br/ download/look-sofrimento.doc

Nasio, J. D. (1991). Hysteria and theory and clinical psycho analysis. Brazil: Jorge Zahar.

Nasio, J. D. (1993). Psychosomatic: Configurations of the object. Brazil: Jorge Zahar.

Nasio, J. D. (2006). A physical pain. Brazil: Jorge Zahar.

Nasio, J. D. (2007). The pain of love. Brazil: Jorge Zahar.

Nasio, J. D. (2009). My body and its images. Brazil: Jorge Zahar.

Nasio, J. D. (2010). The silence in psychoanalysis. Brazil: Jorge Zahar.

Neto, F. K. (2008). Psychoanalysis and the contemporary body. III International Congress of Fundamental Psycho Pathology and IX Brazilian Congress of Fundamental Psycho Pathology. Retrieved from http://www.fundamentalpsychopathology.org/8_ cong_anais/TR_439.pdf

Freud, S. (1896). The etiology of hysteria, imago (Vol. I). Psychological Works. 
Freud, S. (1912). Recommendations to physicians practicing psychoanalysis (Vol. XII). In Rio de Janeiro: Imago, 1912. Ed. Starndard Brazilian (op.cit Electronic Edition).

Freud, S. (1914). Instincts and their vicissitudes (Vol. XIV). In Rio de Janeiro: Imago, 1914. Ed. Starndard Brazilian (op.cit Electronic Edition).

Freud, S. (1914-1916). The history of the psychoanalytic movement articles about metapsychology and other works (Vol. XIV). Ed. Starndard Brazilian (op.cit Electronic Edition).

Freud, S. (1915-1920). Writings on the theory of the unconscious (Vol. II). In Rio de Janeiro: Imago, 1915-1920. Ed. Starndard Brazilian (op.cit Electronic Edition).

Freud, S. (1917/1915). Mourning and melancholia (Vol. XIV). Ed. Starndard Brazilian (op.cit Electronic Edition).

Freud, S. (1923). The ego and the it (Vol. XIX). Ed. Starndard Brazilian (op.cit Electronic Edition).

Freud, S. (1924/1923). Neurosis and psychosis (Vol. XVIII). In Rio de Janeiro: Imago. Ed. Starndard Brazilian (op.cit Electronic Edition).

Freud, S. (1926/1925). Inhibitions, symptoms and anxiety, imago (Vol. XX). Ed. Starndard Brazilian (op.cit Electronic Edition).

Freud, S. (1937). Constructions in analysis (Vol. XII). Ed. Starndard Brazilian (op.cit Electronic Edition).

Freud, S. (1940/1938). Outline of psychoanalysis (Vol. XXIII). Ed. Starndard Brazilian (op.cit Electronic Edition).

Silva, I. S. C., Birth, J. P. B, et al. (2008). Labor relations, subjectivity and objectivity: A reflection theoretical about these three instances in the organizational context. 